\title{
A Study on Incidence and Analysis of Carcinoma of Breast in Early Stage in Tertiary Care Hospital
}

\author{
Authors \\ Dr M. Sukriya M.S ${ }^{1}$, Dr P. Mahesh Kumar. M.S ${ }^{2}$ \\ ${ }^{1,2}$ Senior Assistant Professor, Govt Sivagangai Medical College, Sivagangai \\ Corresponding Author \\ Dr P. Mahesh Kumar. M.S \\ Senior Assistant Professor, Govt Sivagangai Medical College, Sivagangai, India
}

\section{Introduction}

Worldwide, Breast cancer is by far the most common cancer amongst women with an incidence rate more than twice that of colorectal cancer and cervical cancer and about three times that of lung cancer. ${ }^{1,23,4}$. The incidence of breast cancer in India is on the rise and is rapidly, becoming the number one cancer in females pushing the cervical cancer to second place. . $^{5,6,8}$

It is reported that one in 22 women in India is likely to suffer from breast cancer during her lifetime while the figure is definitely more in America where eight being victim of this deadly cancer. The problem with preventing breast cancer is that there is no one cause that can be pinpointed as being the culprit. Of course screening for the presence of BRCA - 1, BRCA - 2 mutations in available, though it must be admitted of being little use in the Indian context. , $^{9} 10,11,12$

The study has been undertaken to emphasis the importance of spreading awareness of the prevalence of this cancer and educating women for self breast examination as a part of early screening step. Health officials must try \& talk about this condition so that women have a say in their own health. Screening procedures like mammography, FNAC \& biopsy, need to be widely publicized so as to what exactly they are letting themselves in for. ${ }^{13,14,15,16,17}$

In this study, we can do

1. To identify the incidence of early breast cancer, in Govt Sivagangai Medical College, Sivgangai

2. To analyze the age wise incidence of carcinoma breast.

3. To analyze the clinical staging at the time of admission.

4. To improve the awareness regarding early detection of breast cancer by means of multi modality screening procedures.

5. To analyze the preventive measures.

6. To analyze the multimodality treatment options in early breast cancer.

\section{Materials and Methods}

Cases of carcinoma breast admitted in Govt Sivagangai Medical College, Sivgangai, during the period of August 2014 to November 2016 were studied, out of which were 1 male patient and he is excluded from the study. 
A detailed history has been taken and thorough general examination was made and cases were studied. These patients were analyzed according to age, clinical Presentation, stage of the disease, menopausal status, and treatment offered. A special attention was given to EBC for whom complete cure is possible there by reducing mortality and morbidity.

\section{Results}

Table 1 Age Distribution

\begin{tabular}{|c|c|c|c|c|}
\hline \multirow{3}{*}{$\begin{array}{l}\text { Age in Years } \\
\text { Up to } 30\end{array}$} & \multicolumn{4}{|c|}{ Cases } \\
\hline & \multicolumn{2}{|c|}{ No. } & \multicolumn{2}{|c|}{$\%$} \\
\hline & 3 & & $4 \%$ & \\
\hline $31-40$ & 20 & \multirow{2}{*}{36} & $28 \%$ & \multirow{2}{*}{$51 \%$} \\
\hline $41-50$ & 16 & & $23 \%$ & \\
\hline $51-60$ & 22 & \multirow{3}{*}{32} & $31 \%$ & \multirow{3}{*}{$45 \%$} \\
\hline $61-70$ & 5 & & $7 \%$ & \\
\hline$>70$ & 5 & & $7 \%$ & \\
\hline Total & 71 & & 100 & \\
\hline
\end{tabular}

Graph 1- Age Distribution Age Distribution
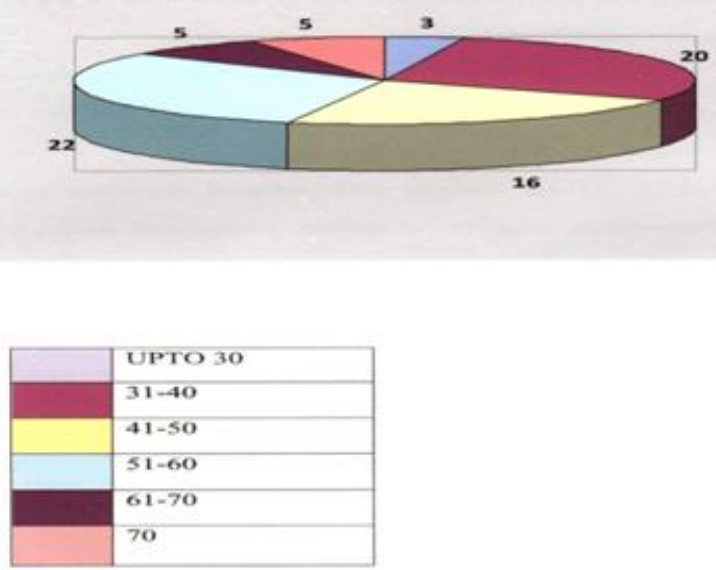

In this group, maximum numbers of patients were found in the age group of 31-50 years whereas the incidence was less in the extremes of age.

\section{Stage at the time of Presentation}

Table 2- Stage

\begin{tabular}{|l|c|c|}
\hline \multirow{2}{*}{ Type of Breast Cancer } & Cases & \\
\cline { 2 - 3 } & No. & $\mathbf{\%}$ \\
\hline Early breast cancer I \& II & 36 & $51 \%$ \\
\hline Locally advanced breast cancer III & 29 & $41 \%$ \\
\hline Advanced Carcinoma breast & 6 & $8 \%$ \\
\hline Total & 71 & 100 \\
\hline
\end{tabular}

\section{Graph 2-Stage}

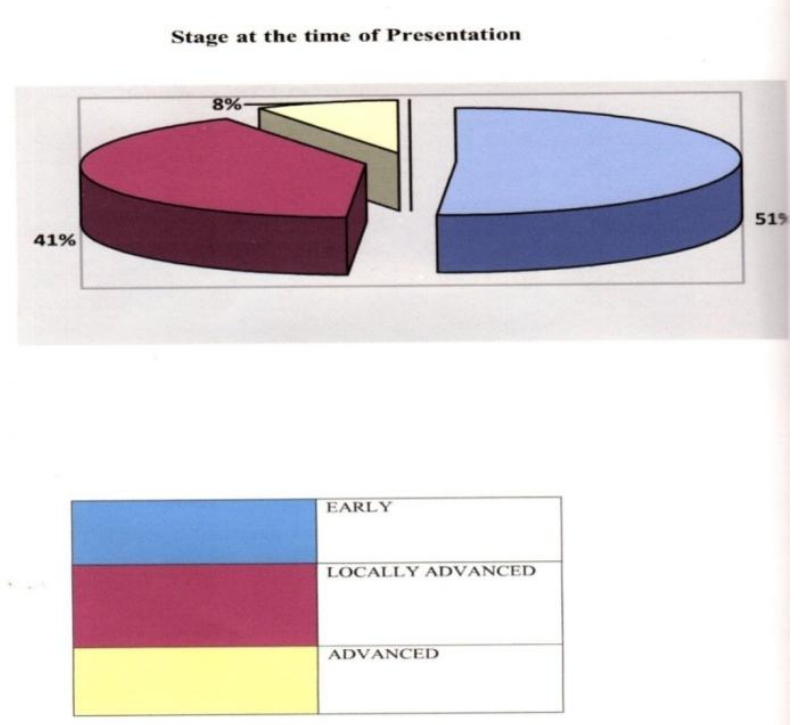

In this study group, $51 \%$ belong to early breast cancer and an equivalent percentage to locally advanced breast cancer. $8 \%$ of patients were in the advanced stage.

\section{Menopausal Status}

Table 3 Menopausal Status

\begin{tabular}{|l|c|c|}
\hline \multirow{2}{*}{ Menopausal Status } & \multicolumn{2}{|c|}{ Cass } \\
\cline { 2 - 3 } & No & \% \\
\hline Pre menopausal & 32 & $45 \%$ \\
\hline Post Menopausal & 39 & $55 \%$ \\
\hline Total & 71 & 100 \\
\hline
\end{tabular}

In this study, $45 \%$ were pre menopausal and 55\% were post menopausal.

\section{Age Wise Distribution of Staging}

Table 4 Age Wise Distribution of Staging

\begin{tabular}{|l|c|c|c|c|c|c|c|c|}
\hline Age group & I & II A & II B & III A & III B & III C & IV & Total \\
\hline Up to 30 & 1 & 2 & 0 & 0 & 0 & 0 & 0 & 3 \\
\hline $31-40$ & 1 & 4 & 7 & 3 & 4 & 0 & 1 & 20 \\
\hline $41-50$ & 0 & 3 & 5 & 2 & 4 & 0 & 2 & 16 \\
\hline $51-60$ & 1 & 3 & 4 & 8 & 2 & 1 & 3 & 22 \\
\hline $61-70$ & 1 & 0 & 3 & 0 & 0 & 1 & 0 & 5 \\
\hline$>70$ & 0 & 1 & 0 & 4 & 0 & 0 & 0 & 5 \\
\hline Total & 4 & 13 & 19 & 17 & 10 & 2 & 6 & 71 \\
\hline
\end{tabular}


Graph 3 Age Wise Distribution of Staging

AGE WISE DISTRIBUTION OF STAGING
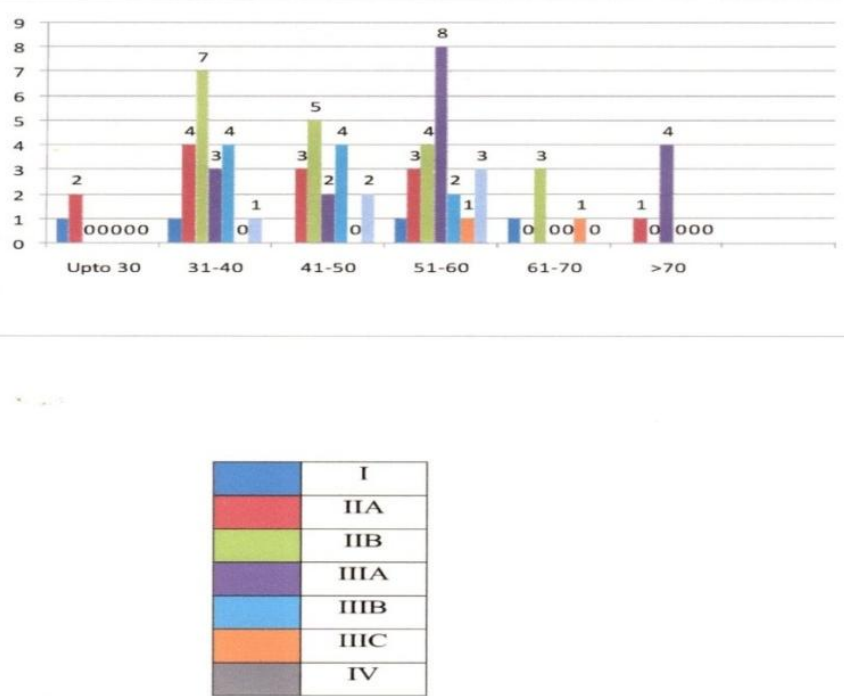

Comparison between our study and SEER study of National Cancer Institute, US. (2004-2008)

Table 5- Comparison with Other Study

\begin{tabular}{|l|c|c|}
\hline Stage of Breast Cancer & Our study & SEER Study \\
\hline I & $5.6 \%$ & $60 \%$ \\
\hline II \& III & $85.9 \%$ & $33 \%$ \\
\hline IV & $8.5 \%$ & $5 \%$ \\
\hline
\end{tabular}

\begin{tabular}{|l|c|c|}
\hline Age at Diagnosis & Our study & SEER Study \\
\hline Under 20 years & $0 \%$ & $0 \%$ \\
\hline $20-34$ yrs & $7 \%$ & $1.9 \%$ \\
\hline $35-44$ yrs & $31 \%$ & $10.2 \%$ \\
\hline $45-54$ yrs & $24 \%$ & $22.6 \%$ \\
\hline $55-64 \mathrm{yrs}$ & $24 \%$ & $24.4 \%$ \\
\hline$>65 \mathrm{yrs}$ & $14 \%$ & $42 \%$ \\
\hline
\end{tabular}

Graph 4- Comparison with other Study

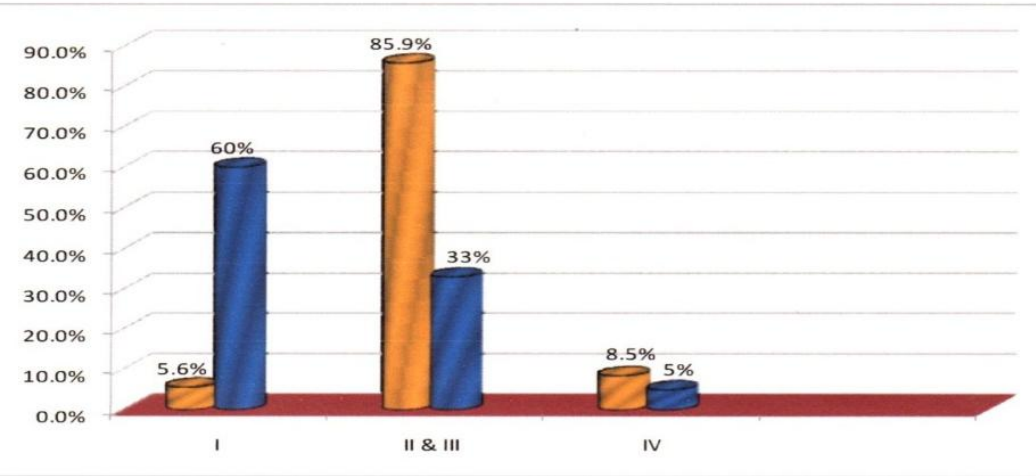




\section{Discussion}

71 cases of Carcinoma breast, admitted in Govt Sivagangai Medical College, Sivgangail, Trichy, are presented in this study. The maximum age incidence of Carcinoma breast in the study group has been 51-60 years of age.

In this study group, about $5.6 \%$ of the patients were with stage I disease. This when compared to the SEER study of National Cancer Institute, US was very low where stage I accounted for $60 \% .^{18,19,20}$ This reflects the need for spreading the awareness among women regarding self breast examination and utilizing screening programme.

Locally advanced breast cancer accounted for $85.9 \%$ where as it is only $33 \%$ in SEER study which again reinforces the need for improvement in health education. Stage IV disease accounted for $8.5 \%$ and $5 \%$ in my study and SEER study respectively. ${ }^{21,22,23,24}$

All patients were assessed preoperatively by clinical examination, biopsy and for metastatic work up chest $\mathrm{x}$-ray and USG abdomen were done.

All patients with early breast cancer underwent modified radical mastectomy and followed by hormonal therapy. Patients with positive nodal status were given adjuvant chemotherapy and radio therapy. Breast conservation therapy has not been attempted because of poor patient surveillance and lack of RT facilities.

All patients with locally advanced breast cancer were given neoadjuvant chemotherapy (3 cycles of CMF regimen) followed by modified radical mastectomy and adjuvant radiotherapy.

To conclude one of the important factors of fight against breast cancer is breast cancer awareness. This more knowledge known about the disease and the more done to check for early warning signs, the better chance for survival. Research and development continues to be done so that one day we can say the history of breast cancer is over.

\section{Conclusion}

The incidence of stage I breast cancer in this study group in only $5.6 \%$ whereas it is $60 \%$ in the SEER study of National Cancer Institute (NCI) of United States. LABC accounted for $85.9 \%$ in the study group whereas its only $33 \%$ in SEER study. The significance of this conclusion is that what cases are classified at a specific instance as LABC once belonged to the category of early breast cancer and subsequently evolved into LABC due to either patient's lack of awareness about the disease or inappropriate interventions or aggressive tumor biology. Thus as prevention is always better than cure it is recommended that the follow up measures can be adopted to address this problem,

1) Improving Health education regarding self breast examination.

2) Screening mammography as mammography is the corner stone of present state of the art approach to the control of breast cancer.

3) General education about early symptoms of the disease and access to medical facilities are important in diminishing breast cancer incidence.

4) Identification of high risk population and specific management. Women at increased risk should be counseled about modifiable risk factors like long term lactation by women in child bearing age, regular physical activity, limitation of post menopausal HRT.

5) Surveillance when family history is positive for breast cancer. Metastatic work up is mandatory.

\section{Bibliography}

1. Courtney M. Townsend, JR., MD., Sally Abston, M.D., Sally Abston, M.D., Jay C.Fish, Md. Surgical Adjuvant Treatment of Locally Advanced Breast Cancer Ann. Surg May 1985 Vol $201 *$ No.5.

2. Jackson VP. Diagnostic mammography. Radiolclin North Am 2004; 42(5):852, vi. 
3. Anderson, EDC. Treatment of breast recurrence after breast conservation. In; Dixon JM, SacchiniV.Dixin, eds. Breast cancer, diagnosis and management. 2000:43:1.

4. Vallasiadou K. Young OE, Dixon JM. Current practices inbreast conservation surgery; results of a questionnaire. $\mathrm{Br}$ JSurg 2003; 90(1):44.

5. Sharon H. Giordano Update on Locally Advanced Breast Cancer the Oncologist, V 01.8.No.6, 521-530, December 2003.

6. Shenkier, T, Weir L, Levine, M, Olivotto I , Whelan T, Reyno L; Steering committee on Clinical Practice Guidelines for the car and Treatment of Breast Cancer, CMAJ 2004 Mar 16:170(6):983-94

7. Lyman GH, G iulano AE, Somerfield MR, et al. ASCOI guideline recommendations for sentinel lymph node biopsy in early stage breast cancer, J. ClinOncol 2005; 23:7703.

8. Giuliano AE, Kirgan DM, Guenther JM, et al. LYMPHATIC MAPPING and sentinel lymphadenectomy for breast cancer. Ann Surg 1994;220:391.

9. Fletcher SW, Elmore JG.Mammographic screening for breast cancer, $N$ Eng J Med 2003;348:1672.

10. Haagensen CD Stout AP. Carcinoma of the breast. H . Criteria of operability. Ann Surg 1943:118:857-870, 1032-1054.

11. Rubens RD. the management of locally advanced breast cancer Br.J Cancer 1992; 65:145-147.

12. Hortobagyi GN, Buzdar AU Locally advanced breast cancer; a review including the MD Anderson experience, In :Ragaz J, Ariel IM, eds. High - Risk Breast Cancer, Berlin: Springer - verlag, 1991: 382-415.

13. Rustogi. A Budrukkar A, Dinshaw K, Jalali. R. management of Locally advanced breast cancer: Evolution \& current practiced J.Caner Res Ther - Mar 2005, 1:21-30.
14. Touboul E, Lefrance JP, Blondon J, Ozsahim M, Mauban S, Scheartz LH, Schlienger M, Laugier A, Guerin RA. Multidisciplinary treatment approach to locally advanced non-inflammatory breast cacer using chemotherapy and radiotherapy with or without surgery. Radiother Oncol, 1992 Nov:25 (3): 16775.

15. Kim R. Osaki A, Tanabe K, Toge T. Neoadjuvant chemotheraphy for locally advanced breast cancer with stage 3 HIB Oncol Rep. 2004 Jun: 11(6): 1265-72.

16. Ahern V, Barraclough B, Bosch C, Langlands A, Boyages J. Locally advanced breast cancer: defining an optimum treatment regimen Int J RadiatOncolBiol Phys. 1994 Mar 1:28(4): 867-75.

17. Eniu A, Carlson RW. Azoz Z. Bines J, Hortobagyi GN, Bese NS, Love RR, Vikram B, Kurkure A, Anderson BO Breast cancer in limited-resource countries: treatment and allocation of resources Breast J 2006 Jan _ Feb; 12 Supp1 1:S38-53.

18. Beenken SW, Bland KI. Breast cancer genetics. In: Ellis CN, ed.Inherited cancer syndromes:current clinical management. Newyork:2004:91.

19. Bland KI, Chang HR, Chandler GS, et al. MRM nadSM. In Bland KI, Copeland EM III, eds. The breast: comprehensive managemebt of benign and malignant disorders. WB Saunders, 2004:865.

20. Jay r. harrist, Marc E.Lippman, Monica Morrow C. Kent Osborne, Diseases of the Brest $4^{\text {th }}$ Ed.M.D. Anderson Cancer Center experience J ClinOncol 2001:19;628.

21. Veronesi U, Bonadonna G. ZurridaS,et al. Conservation surgery after primary chemotherapy in large carcinomas of the breast Ann Surg 1995;612.

22. Valagussa $P$, Zambetti M, Bignami Pet al T3b-T4 breast cancer; factor affecting 
results in combined modality treatments, ClinExp Metastasis. 1983;1:191-202.

23. Taylor G, Meltzer A Inflammatory carcinoma of the breast American Journal of Cancer 1938:33;33.

24. M. Cariati, T.M. Bennett-Britton, S.E. Pinder, A.D. Purushotham Inflammatory "breast cancer surgical oncology 14(20050 133-143. 